\title{
Evaluation of PC12 Cell Neural Differentiation on Graphene Coated ITO Microchips
}

\author{
Tansu Gölcez ${ }^{1}$, Fikri Seven ${ }^{1}$, Ozan Karaman², Mustafa ŞEN ${ }^{2}$ \\ ${ }^{1}$ Department of Biomedical Technologies, Izmir Katip Celebi University, Izmir, Turkey \\ ${ }^{1}$ Department of Biomedical Engineering, Izmir Katip Celebi University, Izmir, Turkey \\ ttansugolcezz@gmail.com, mustafa.sen@ikcu.edu.tr
}

\begin{abstract}
In this study, the impact of graphene on neuronal differentiation of PC12 cells into neuron-like cells was evaluated in conjunction with electrical stimuli. First, an ITO (Indium Tin Oxide) microchip with a certain number of electrodes was fabricated using photolithography and then a chemically synthesized graphene was coated on the microchip. The electrical stimulation was applied through the ITO-microchip. Following optimization of neuronal differentiation conditions, the effect of AC and DC electrical stimulation on both bare and graphenecoated ITO-microchips for neuronal differentiation was investigated. According to the results, it was observed that electrical stimulation with direct current for $\mathbf{3 0}$ minutes caused a large degree of neuronal cell differentiation on the graphene coated ITO-microchips. The results were also verified by real-time qPCR.
\end{abstract}

Keywords-PC12 cells, ITO, microchip, neural differentiation, graphene.

\section{INTRODUCTION}

Electrical stimulation (ES) is one of the most challenging studies about nerve regeneration on both peripheral and central nerve injuries and damage for promoting axonal outgrowth. A study showed that electrical stimulation $(20 \mathrm{~Hz}, 100$ microseconds, 3 $\mathrm{V})$ increased the quantity of remyelination as looking at gene ( $\mathrm{P} 0$ and brain-derived neurotrophic factor) expression profiles and co-cultured cells and tissues. ES elevates the thickness of myelin sheat and promotes regeneration as axonal outgrowth [1]. Huang and coworkers showed also that in impaired peripheral nerve damage in vivo, electrical stimulation (ES; $3 \mathrm{~V}, 20 \mathrm{~Hz}, 20 \mathrm{~min}$ ) accelerates the nerve regeneration and functional healing as providing the recovery in slow rate nerve regeneration. They observed that ES greatly increased the size and level of regenerated axons, the width of myelin sheath, and also the amount of retrograde-labeled Fluoro-Gold motoneurons and sensory nerve cells. indicating that brief ES to proximal nerve stumps is capable of fostering nerve regeneration in delayed nerve injury repair with differing prolonged periods of time, with the longest 24 weeks [2]. Gordon showed that lowfrequency electrical stimulation (LFES) speeds up motor and sensory axon outgrowth through the nerve injury points, promoting nerve regeneration and target reinnervation even after prolonged surgical reconstruction of damaged nerves [3].

The primary goal of the study was to evaluate the impact of graphene in conjunction with electrical stimulation on neuronal differentiation of PC12 cells into neuron-like cells. To that end, an ITO microchip with a certain number of electrodes was fabricated using photolithography and then a chemically synthesized graphene was coated on the microchip. Following optimization of neuronal differentiation conditions, the impact of AC and DC electrical stimulation on neuronal cell differentiation was investigated, respectively on both bare and graphene coated ITO-microchips. Lastly, a real-time qPCR test was carried out to verify the obtained results.

\section{METHOD}

\section{A. Fabrication of ITO Microchip}

Fabrication of the microchip and the production of masks for photolithography, which will form the basis for the new platform developed. Vectorworks program was used for microchip design. The distance between the electrodes was determined as $50-100 \mu \mathrm{m}$ in order to achieve a successful result. It was thought that this distance will be sufficient for the extension of axon and dendritic structures. After the production of chrome masks, the fabrication of Indium Tin Oxide (ITO) interdigitated array electrode (IDA) microchips was made with use of photolithographic methods [4-8]. In the following microproduction step, patterning was carried out using chrome lithography mask produced specifically for the microchip. Firstly, a positive photoresist was spun coated on the subsrate. After baking the photoresist, a UV mask was used to pattern the positive photoresist. The UV light exposed areas of the photoresist become soluble and sensitive to a developer solution. In the next step, developer solution was used to remove the UV patterned regions. In these regions, ITO film becomes exposed and by using ion beam etching these regions they were removed physically. Lastly, the remaining photoresist, were removed by using aseton. These microchips were used troughout the study (Fig. 1)

\section{B. Graphene Synthesis and Coating}

First, to reduce the density of impurities or defects on commercially available copper $(\mathrm{Cu})$ foils, the foils were annealed at high temperature and the surface was cleaned by the chemical-mechanical polishing (CMP) method. Graphene was synthesized on polished copper and cleaned using chemical vapor deposition method at atmospheric pressure. Chemical vapor deposition (CVD) is the process of accumulating films in the vapor phase of materials by separating chemicals on the surface of a substrate. The $\mathrm{Cu}$ Foil was placed in a CVD quartz tube with hydrogen $\left(\mathrm{H}_{2}, 80 \mathrm{sccm}\right)$ and argon (Ar, $\left.1000 \mathrm{sccm}\right)$ flow. The temperature was raised from room temperature to 
$1079^{\circ} \mathrm{C}$ and annealed with the same gas atmosphere for 30 minutes. Graphene was synthesized at $1079^{\circ} \mathrm{C}$ with a flow of carbon source methane gas for 1 minute, and then the medium in which it was found was cooled to room temperature in an $\mathrm{Ar} / \mathrm{H}_{2}$ atmosphere. After synthesis, poly (methyl methacrylate) (PMMA) was coated on graphene films and then left in acid solution $\left(\mathrm{FeCl}_{3}\right)$ for 1 hour to remove copper. After copper was completely abraded, graphene films containing PMMA were rinsed and cleaned several times with pure water. After the films were cleaned, they were transferred to the previously prepared ITO microchips with the dipping technique (fishing method). Graphene transferred ITO microchips were dried in the drying oven for 20 minutes. Finally, the protective layer, the polymer, was cleaned for 3 minutes in hot acetone, IPA (isopropyl alcohol) and ethanol, respectively, and dried with a nitrogen gun [9]. Thus, the synthesized graphene was coated on ITO microchips.

\section{Cell Culturing and Electrical Stimulation of Cells on Graphene Coated-ITO Microchip}

The purchased cells are centrifuged in a "falcon" tube (centrifuge tube) at $1000 \mathrm{rpm}$ at $+4{ }^{\circ} \mathrm{C}$ after $1 \mathrm{ml}$ RPMI 1640 $(10 \%$ DHS $+1 \%$ FBS $+1 \%$ L-Glutamine $+0.1 \%$ Gentamycin $)$ homogenized with the help of vortex in the medium. This cell suspension is then transferred to cell culture flasks that is coated with collagen for better attachment before with containing $4 \mathrm{ml}$ growth medium. Subsequently, these flasks are placed in an incubator containing $5 \% \mathrm{CO}_{2}$ at $37^{\circ} \mathrm{C}$, allowing the cells to

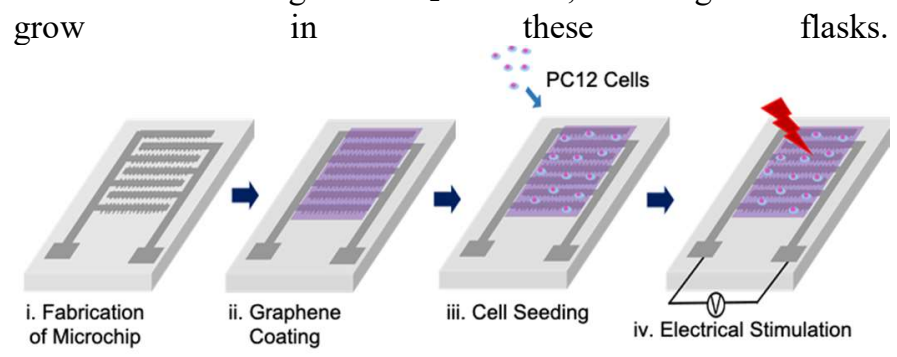

Fig. 1. Electrical stimulation of cells on graphene coated microchip

Graphene coated ITO microchips were sterilized overnight with UV light of the 2 nd class safety biological cabinet to prevent any risk of contamination. The next day, samples taken from UV light were processed for collagen coating. Collagen solution (approximately $100 \mu \mathrm{l}$ ) in the amount to be collagen coated was dropped on each area of the graphene coated part and taken into the incubator $\left(37.5^{\circ} \mathrm{C}\right)$ used for cell culture containing 5\% $\mathrm{CO}_{2}$. Microchips that were left in the incubator until dry (about 2 hours) were taken back to the cell culture cabinet for sterilization. Microchips were sterilized under UV light for at least 30 minutes to minimize any risk of contamination in the cell culture cabinet. After the cell seeding process was done on the microchip, the microchip was taken into a $35 \mathrm{~mm}$ petri dish, since the cells would need a container to feed the required nutrient. Since electrical stimulation will be done after the seeding process, the wires of the microchip in the petri are fixed with the help of tape on the outer edge of the petri dish in order not to damage the cells. At the last stage of the passages, $5 \mathrm{ml}$ of medium was removed and the cells were suspended and $1 \mathrm{ml}$ of the suspended solution was transferred to collagen coated flask and passaged in a 5:1 ratio. As the remaining cell suspension will be sown on the microchip, counting is performed on the hemocytometer first, and then, after making the necessary calculations, $5 \times 10^{3}$ cells are added to the $\mathrm{cm}^{2}$ on the microchip. As PC12 cells are semi-suspended cells and not easy to hold, they were kept in the incubator so that they could hold onto the surface for half an hour. After the incubation, $5 \mathrm{ml}$ of medium was added to the petri dish to grow the cells on the microchip and the cells were incubated for 24 hours until stimulation or continue to the experiments (Fig. 1).

\section{Real-Time Polymerase Chain Reaction (RT-PCR)}

For PCR, the mRNAs of the cells must first be extracted and translated into cDNA. A commercial kit was used for mRNA extraction. Firstly, the cells are washed normally with PBS solution 1-2 times and trypsin is added on the cells for liftingoff. mRNAs of cells are extracted via kit and all sections of this procedure is carried out in a cell culture hood to inhibit the contamination. As a result of this process, mRNA molecules were collected in the ependorph tube. Before converting the isolated mRNA molecules to cDNA, absorbance measurement was made in the NanoDrop device and the dilution rate was determined. According to the absorbance values, the best result was obtained in the dilution ratio of $1: 10$. Samples were taken to convert mRNA molecules into cDNA. During this process, the QuantaBio cDNA synthesis kit was used and all procedures were performed according to the protocol included in the kit. At the end of this step, mRNA molecules have been converted to cDNA. For PCR processing, cDNAs were diluted 1:10 with an autoclaved ultrapure water. All the processes carried out at this stage were done on ice. After the forward (forward - F) and reverse (reverse - R) primers for each gene (Synapsin-I, GAP43 and GAPDH (as a housekeeping gene)) are mixed and spinned with the help of vortex, each gene's $F$ and $R$ primers are taken and combined in an ependorph tube. Later, mixtures of SYBR green, ultrapure water, ROX (carboxy-X-rhodamine), dNTPs, Taq polymerase, $\mathrm{MgCl} 2$ and pre-prepared gene primers at the rates specified in RT-PCR protocol were combined and "master mix" solutions were prepared for each gene separately. The result of the first process is 1:10 diluted cDNA solution and "master mix" solution is mixed for each gene separately and RT-PCR device (Applied BioSystems) in a tube (3 separate tubes prepared for each gene). PCR analysis was performed by placing into RT-PCR device.

\section{RESULTS}

To study the effect of graphene on differentiation of nerve cells, the differentiation of PC12 cells was investigated using the commercially available nerve growth factor. 4 different groups were used for the experiment: ITO control and ITO microchip with direct current (DC) electrical stimulation, graphene coated ITO microchip and graphene coated ITO microchip with direct current electrical stimulation.

\section{A. Electrical Stimulation of PC12 Cell}

When comparing ITO control and ITO DC group, electrical stimulation caused the cells to orient and accumulate on the 
electrodes. In ITO DC group, differentiation was not really observed but it compares with graphene coated ITO with direct current electrical stimulation experiment, there are many neurite extensions. Neurite extensions was observed in control groups so cells could be differentiated in every situation in the presence of NGF (Fig. 2). Considering these conditions, graphene coated microchips have more neurite lengths and number of neurites per cell so it might be said graphene accelerates the nerve differentiation and making new connections between cells due to nanostructure and electrically conductivity of graphene.ITO microchip with DC electrical stimulation group was observed day by day and images of first, third, fifth and seventh day was taken from the same place of microchip under microscope (Fig. 3 ). Direct current electrical stimulation provides to oriented the cells through the electrodes of microchip. When number of day increases, cells more oriented through the electrodes. It provides to make better connections between nerve cells by extensions.
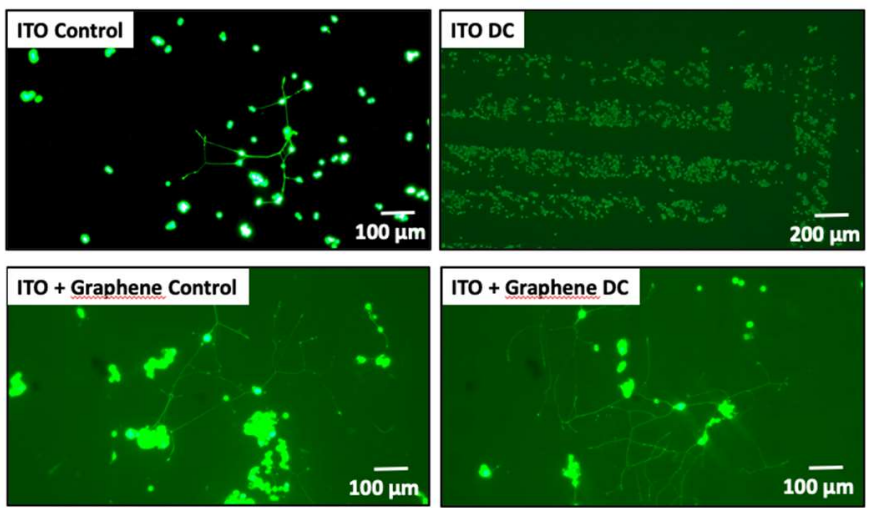

Fig. 2. Pictures of PC12 cells grown with and without electrical stimulation on the ITO microchip and graphene coated ITO microchip from days 5.
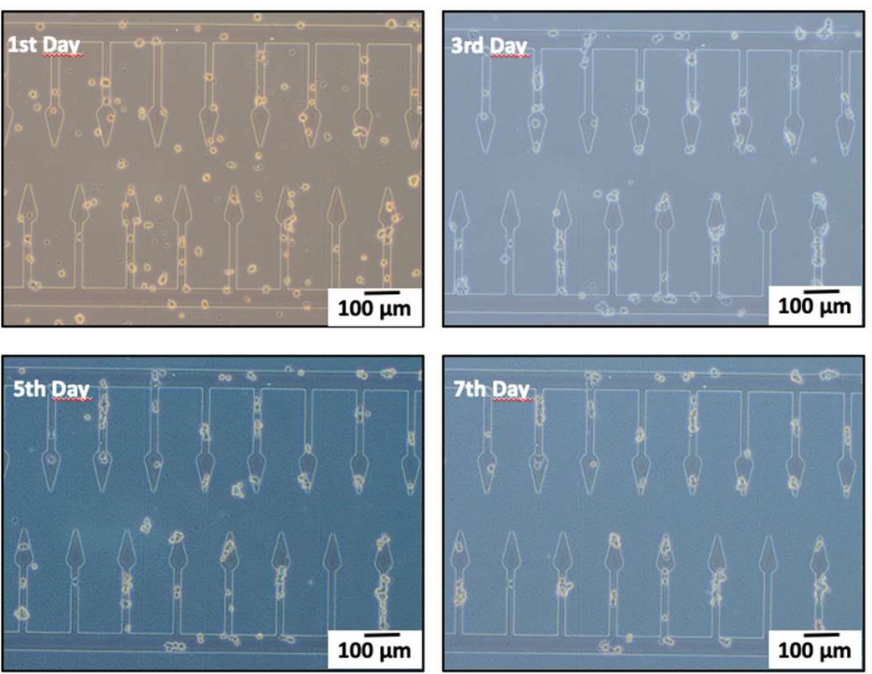

Fig. 3. Pictures of PC12 cells grown with direct current electrical stimulation on the ITO microchip from days $1,3,5$ and 7.

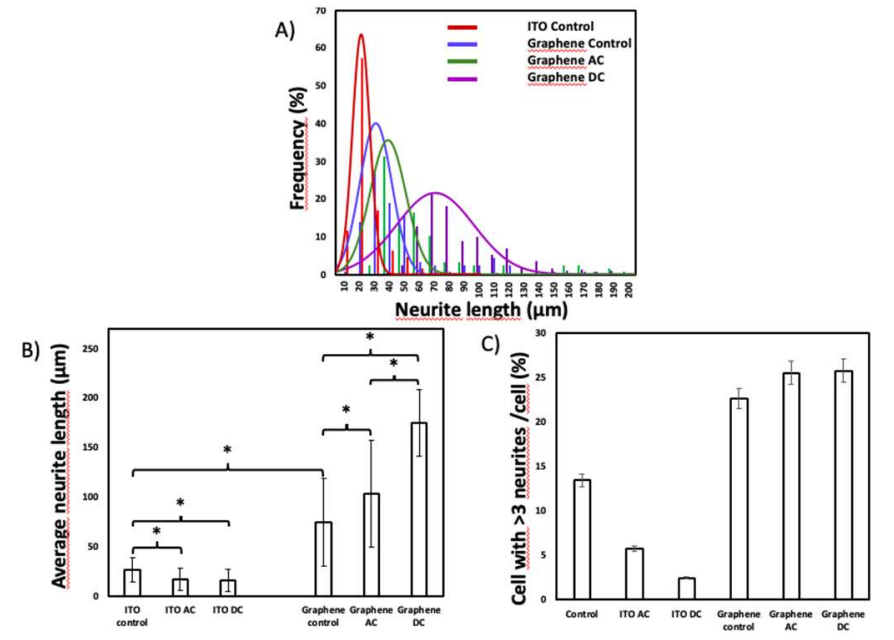

Fig. 4. Pictures of PC12 cells grown with alternative and direct current electrical stimulation and without electrical stimulation on ITO microchip and graphene coated ITO microchip.

When comparing all groups, the best neurite lengths are found in the graphene DC group. Graphene provides more longer neurites according to ITO groups. Graphene coated ITO microchip and graphene coated ITO microchip with alternative current showed nearly the same neurite number and length so alternative current is not working well. Graphene coated ITO microchip with direct current have the longest neurites as average (A). Graphene coating is known as good for providing more longer neurites. When comparing ITO groups amongst themselves average neurite lengths are nearly same also neurite lengths of alternative current and direct current groups. ITO control group showed without electrical stimulation ITO microchip had a better effect on PC12 cells. Comparing control groups of ITO and graphene coated ITO microchip groups, graphene coated control group showed better effect as longer neurites as shown in previous figure. When graphene groups compared amongst themselves, graphene coated ITO microchip with direct current electrical stimulation showed more longer neurites because of their better orientation (B). Bare ITO groups compared amongst themselves, ITO control group have highest number of neurites per cells so electrical stimulation on bare ITO microchip has been shown to adversely affect. In all graphene groups, nearly the same number of neurites per cell but in direct current electrical stimulation on graphene coated ITO microchip has the highest number of neurites per cell. Electrical stimulation investigates the neurite outgrowth and number of neurites per cells on the graphene coated ITO microchip surface due to graphene's conductivity and nanostructure on microchips. (C). PC12 nerve cells tend to grow better on graphene and remove more neurites (Fig. 4).

\section{B. Real-Time PCR}

PCR (Polymerase Chain Reaction) is a process applied to gene sequence to replicate enzymatically in a certain region of DNA [10]. Differentiation of PC12 cells were obtained and showed by pictures but for the precision of data gene expression profile must be checked. Gene of differentiated cells are copied and their optimization were done by PCR method. In this experiment, SIN-1 (3-morpholinosydnonimine) and GAP43 
(Growth Association Protein) genes are used for detecting the differentiation gene and GAPDH (Glyceraldehyde-3-phosphate dehydrogenase) gene is used for housekeeping gene [11-14]. According to $\mathrm{qPCR}$ results, electrical stimulation on graphene coated IDA microchips according to graphene coated without electrical stimulation shows better differentiation activity from genes of differentiated PC12 cells (Fig. 7). qPCR results are verified the results of previous data (Fig. 4).

\section{GENE EXPRESSION PROFILE}

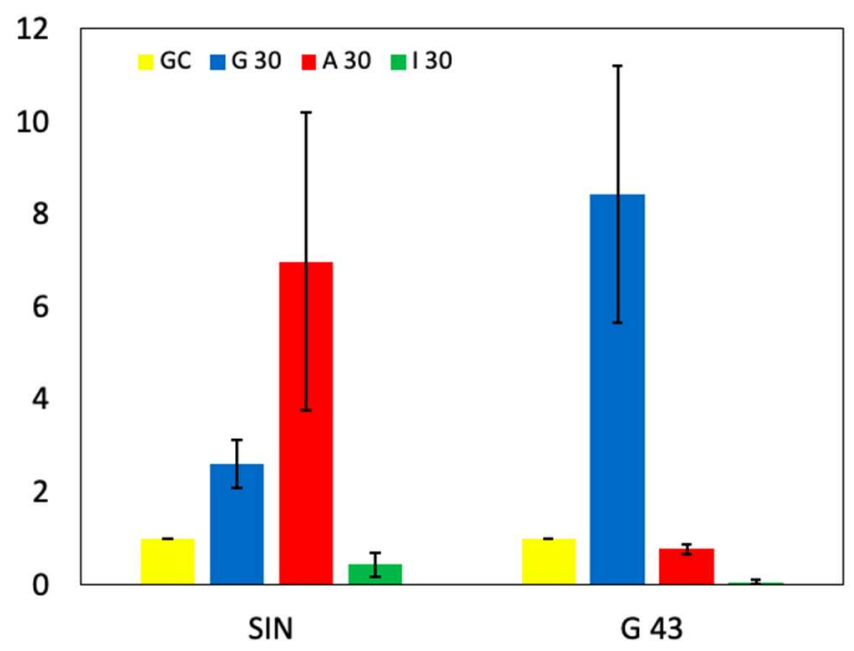

Fig. 5. Graph has been obtained from $\mathrm{qPCR}$ results of $\mathrm{PC} 12$ cells are differentiated with NGF. (GC: Graphene coated ITO Microchip, G30: Graphene coated ITO microchip with direct current electrical stimulation applied for $30 \mathrm{~min}$, A30: ITO microchip with alternative current electrical stimulation applied for $30 \mathrm{~min}$, I30: ITO microchip with direct current electrical stimulation applied for $30 \mathrm{~min}$.)

\section{CONCLUSION}

Synapse formation between cells provides communication and signals can be received from these cells to investigate some nervous system diseases and treatments. The first step of forming such connections on a chip is to induce spreading of neuronal extensions. In this study, the impact of graphene on neuronal differentiation of PC12 cells into neuron-like cells was evaluated in conjunction with electrical stimulation. To apply the electrical stimulation, an ITO microchip was successfully fabricated using photolithography. Next, the concentration of NGF was optimized and $100 \mathrm{ng} / \mathrm{ml}$ was found to be sufficient to induce the neuronal differentiation of PC12 cells. When cells were induced to differentiate without electrical stimulation, they demonstrated a much better differentiation behavior on graphene coated ITO-microchips than bare microchips. Although both $\mathrm{AC}$ and DC electrical stimulation negatively affected neuronal differentiation on bare ITO microchips, they both demonstrated a significantly affirmative effect in inducing neuronal differentiation on graphene coated ITO-microchips. When the effects of AC and DC on graphene-coated ITOmicrochips were compared, it was observed that the DC electrical stimulation applied in the presence of NGF for 30 minutes gave rise to the highest level of neuronal extension spreading. The positive effect of DC electrical stimulation was also verified with $\mathrm{RT}-\mathrm{qPCR}$ test.

\section{ACKNOWLEDGMENT}

This research was supported by the Scientific and Technological Research Council of Turkey (TUBITAK) (Project No: 215E003).

\section{REFERENCES}

[8] F. Seven, T. Gölcez, M. Şahinler, A. Şendemir, O. Karaman, and M. Şen, "Prolonged Electrical Stimulation of Neuronal PC12 Cells Using a Microchip," in 2019 Medical Technologies Congress (TIPTEKNO), 2019, pp. 1-4: IEEE.

[9] G. Ersü, F. Güneş, A. Aykaç, and M. Can, "Improving the sheet resistance of cvd-graphene films via doping," Anadolu University of Sciences \& Technology-B: Theoretical Sciences, vol. 6, no. 2, 2018.

[10] R. K. Saiki et al., "Enzymatic amplification of beta-globin genomic sequences and restriction site analysis for diagnosis of sickle cell anemia," vol. 230, no. 4732, pp. 1350-1354, 1985.

[11] N. Wang et al., "Possible role of miR-204 in optic nerve injury through the regulation of GAP-43," Molecular medicine reports, vol. 17, no. 3, pp. 3891-3897, 2018.

[12] S.-H. Moon, Y.-J. Lee, S. Y. Park, K.-Y. Song, M.-H. Kong, and J.-H. J. J. o. K. N. S. Kim, "The Combined Effects of Ginkgo Biloba Extracts and Aspirin on Viability of SK-N-MC, Neuroblastoma Cell Line in Hypoxia and Reperfusion Condition," Journal of Korean Neurosurgical Society, vol. 49, no. 1, p. 13, 2011.

[13] G. M. Cahuana, J. R. Tejedo, J. Jiménez, R. Ramírez, F. Sobrino, and F. J. J. E. c. r. Bedoya, "Nitric oxide-induced carbonylation of Bcl-2, GAPDH and ANT precedes apoptotic events in insulinsecreting RINm5F cells," Experimental cell research, vol. 293, no. 1, pp. 22-30, 2004.

[14] M.R. Hara, M.B. Cascio, and A. Sawa. "GAPDH as a sensor of NO stress." Biochimica et Biophysica Acta (BBA)-Molecular Basis of Disease, vol. 1762, no. 5, pp. 502-509, 2006. 